\title{
Composição granulométrica do filtro ascendente para pós-tratamento de lixiviado de aterro sanitário
}

\author{
Granulometric composition of the upflow filter for post-treatment of landfill leachate
}

\author{
Eduardo Hideo Fujii' $\odot$, Renan Borelli Galvão** $\odot$, Josemarque Lima Rosa' ${ }^{\oplus}$, \\ Fernando Fernandes' ${ }^{\circledR}$, Emília Kiyomi Kuroda' ${ }^{\circledR}$
}

$\square$

\section{RESUMO}

O lixiviado de aterro sanitário apresenta composição variável e complexa e pode ter elevadas concentrações de nitrogênio amoniacal e matéria orgânica biodegradável e recalcitrante. Devido ao potencial altamente poluidor dos lixiviados estabilizados, além do tratamento biológico convencional, faz-se necessária, em alguns casos, a realização de pós-tratamento para remoção da matéria orgânica recalcitrante, de maneira a atender à legislação vigente. Nesse contexto, os ensaios de coagulação seguida de filtração ascendente em pedregulho como pós-tratamento foram realizados com o objetivo de estabelecer a composição granulométrica que resultasse na melhor condição de eficiência em relação à remoção de matéria orgânica recalcitrante e operação, visando à aplicação do sistema em escala real. Para todos os ensaios, foram aplicados taxa de filtração constante de $15 \mathrm{~m}^{3} \cdot \mathrm{m}^{2}$.dia ${ }^{-1}$ e dosagem de ferro de $400 \mathrm{mg} \mathrm{L}^{-1} \mathrm{em}$ pH 4,O. A duração das carreiras de filtração, bem como a qualidade do efluente tiveram forte influência em relação à composição granulométrica do filtro, podendo-se constatar a necessidade do emprego de areia fina em sua composição, a fim de garantir a eficiência do tratamento. A concepção técnica de pós-tratamento por coagulação seguida da filtração ascendente com a composição granulométrica definida neste trabalho (tipo 4) foi eficiente para a remoção de matéria orgânica recalcitrante, com remoções de $82,4 \%$ de demanda química de oxigênio (valor residual de 194 mg..ㄱ), de 98,8\% de cor verdadeira (valor residual de $49 \mathrm{uH}$ ), de 94,3\% de carbono orgânico total (valor residual de 52 mg..'') e duração de carreira de filtração de 22,6 horas, sem ocorrência de transpasse.

Palavras-chave: lixiviado de aterro sanitário; pós-tratamento físico-químico; filtração ascendente em pedregulho; composição granulométrica.

\begin{abstract}
Landfill leachate presents variable and complex composition and may have high concentrations of ammoniacal nitrogen and biodegradable and recalcitrant organic matter. Due to the high polluting potential of stabilized leachate, in addition to conventional biological treatment, it is necessary in some cases to perform post-treatment to remove recalcitrant organic matter to meet the current legislation. In this context, the coagulation followed by upflow gravel filtration experiments were carried out with the objective of establishing the granulometric composition that resulted in the best efficiency condition in relation to the removal of recalcitrant organic matter and operation, aiming at the system's application in real scale. For all the tests, a constant filtration rate of $15 \mathrm{~m}^{3} \mathrm{~m}^{-2}$ day ${ }^{-1}$ and an iron dosage of $400 \mathrm{mg} \mathrm{L}^{-1}$ at $\mathrm{pH} 4.0$ were applied. The duration of filtration cycles, as well as the quality of the effluent were strongly influenced by the filter's particle size, and it is possible to verify the need of using fine sand in its composition to guarantee the treatment's efficiency. The technical design of post-treatment by coagulation followed by upflow gravel filtration with the granulometric composition defined in this study (type 4) was efficient in removing recalcitrant organic matter, with removals of $82.4 \%$ for COD (residual value of $194 \mathrm{mg} \mathrm{L}^{-1}$ ), $98.8 \%$ for true color (with residual value of $49 \mathrm{uH}$ ), and $94.3 \%$ for TOC (residual value of $52 \mathrm{mg} \mathrm{L}^{-1}$ ), resulting in a filtration cycle duration of $22.6 \mathrm{~h}$, with no loss of filtered solids.
\end{abstract}

Keywords: landfill leachate; physical-chemical post-treatment; upflow gravel filtration; granulometric composition.

\section{INTRODUÇÃO}

O aumento na produção de resíduos sólidos e a sua destinação final têm sido, nas últimas décadas, um dos grandes desafios no âmbito da gestão ambiental, especialmente em países em desenvolvimento. No Brasil, a geração de resíduos sólidos em 2015 foi estimada em torno de 79,9

milhões de toneladas. Desse montante, 90,8\% foram coletados e 58,7\% foram dispostos em aterros sanitários (ABRELPE, 2015).

A disposição desses resíduos em aterro sanitário continua sendo a forma de manejo mais aceita e empregada no país, especialmente pela disponibilidade de grande área territorial e condições climáticas. 
Além da viabilidade econômica, o aterramento sanitário pode minimizar as agressões ambientais e permitir a decomposição controlada de resíduos até sua transformação em material inerte e estabilizado (KIETLINSKA; RENMAN, 2005; RENOU et al., 2008).

Apesar das vantagens desse método, esse tipo de disposição final concorre para a formação de subprodutos em razão da decomposição física, química e biológica dos resíduos sólidos depositados, os quais são solubilizados na água, gerando gás metano e um líquido de coloração escura e altamente poluidor denominado chorume, percolado ou lixiviado.

O lixiviado de aterro sanitário possui composição variável e complexa, a depender do tipo de resíduo sólido depositado, idade do aterro, grau de compactação, condições climáticas locais, entre outros fatores. Em geral, contém altas concentrações de matéria orgânica (biodegradável e refratária), além de concentrações de nitrogênio amoniacal, metais pesados, compostos orgânicos clorados e sais inorgânicos (KJELDSEN et al., 2002; LI et al., 2009).

Lixiviados de aterros em operação há mais de 5 a 10 anos são comumente chamados de lixiviados estabilizados e costumam conter compostos de difícil biodegradação, ou recalcitrantes, como as substâncias húmicas (ácidos húmicos e fúlvicos e huminas), com estruturas moleculares complexas e heterogêneas e massa molecular elevada (HUO et al., 2008). Por não serem facilmente degradadas, a acumulação dessas substâncias no meio pode provocar impactos indesejáveis no ambiente.

Visando à preservação do meio ambiente e à garantia da qualidade de vida da população, as legislações estão cada vez mais restritivas em relação aos padrões de lançamento de efluentes e de enquadramento dos corpos aquáticos, o que requer a adoção de um sistema de tratamento eficiente para o lixiviado.

Os processos biológicos, embora eficientes para remoção de matéria orgânica biodegradável e nitrogênio, apresentam ação limitada sobre a matéria orgânica recalcitrante, necessitando de pós-tratamento adequado para removê-la, a fim de atender às legislações vigentes (BAIG et al., 1999). Nesse sentido, diversas tecnologias de pós-tratamento físico-químico de lixiviado de aterro sanitário têm sido estudadas, como a coagulação-floculação-sedimentação, processos oxidativos avançados e adsortivos, precipitação química, filtração em membrana, entre outros (AMOKRANE; COMEL; VERON, 1997; AZIZ et al., 2007; DIAMADOPOULOS, 1994; FELICI et al., 2013; KAWAHIGASHI et al., 2014; LINDE; JÖNSSON; WIMMERSTEDT, 1995; MALER et al., 2015; MARAÑÓN et al., 2008; RENOU et al., 2008; TATSI et al., 2003; WANG; SMITH; EL-DIN, 2003).

Os trabalhos apontam a coagulação-floculação-sedimentação aplicada ao pós-tratamento de lixiviado como eficiente em relação à remoção de matéria orgânica recalcitrante correlacionada à cor verdadeira e parte da demanda química de oxigênio (DQO) (FELICI et al., 2013; KAWAHIGASHI et al., 2014; POZZETTI et al., 2013).
No entanto, essa técnica requer elevado tempo de sedimentação devido à baixa velocidade de sedimentação dos flocos formados, o que dificulta o tratamento por escoamento contínuo, sendo, portanto, um fator limitante para sua aplicação em escala real em aterros de médio e grande porte.

Por outro lado, sabe-se que a filtração ascendente aplicada ao tratamento de água após coagulação apresenta vantagens, como possível redução do consumo de coagulante, menor área requerida, melhor aproveitamento da camada filtrante, filtração no sentido da camada de maior granulometria para a de menor, carreiras de filtração mais longas, melhor aproveitamento da carga hidráulica disponível e desempenho eficiente para remoção de turbidez, cor verdadeira e algas (DI BERNARDO; DANTAS, 2005).

A filtração ascendente em pedregulho tem como vantagem a maior robustez por conta da capacidade de retenção de sólidos no fundo do filtro, de onde podem ser mais facilmente removidos através da execução de descargas de fundo, além de resultar em durações de carreira mais prolongadas (KURODA; DI BERNARDO; PAULA, 2003). Dessa forma, a composição granular em pedregulho torna essa técnica promissora para o pós-tratamento de lixiviado por causa da robustez em relação à elevada carga contaminante/poluidora do lixiviado, simplicidade operacional, se comparada ao filtro ascendente de areia grossa, e compatibilidade às vazões de lixiviado por empregar taxas de filtração inferiores.

A utilização da filtração ascendente em areia grossa para o tratamento de lixiviado por Castilhos Junior, Dalsasso e Rohers (2010) apresentou remoções de cor, DQO, demanda bioquímica de oxigênio (DBO) e metais pesados, porém, os autores recomendaram estudos adicionais sobre a composição granulométrica do filtro, a fim de aumentar a duração da carreira de filtração. Vale ressaltar que não foram encontrados, na literatura internacional, trabalhos sobre a aplicação de filtração ascendente em lixiviados de aterro sanitário.

Diante do exposto, este trabalho teve como objetivo estabelecer a composição do material granular mais adequada para o filtro ascendente aplicado ao pós-tratamento de lixiviado estabilizado de aterro sanitário, para remoção de matéria orgânica recalcitrante sob condições operacionais visando à aplicação do sistema em escala real.

\section{METODOLOGIA}

\section{Lixiviado bruto}

O lixiviado bruto foi proveniente do aterro controlado da cidade de Londrina, Paraná, operado entre 1974 e 2010, o qual é caracterizado como estabilizado. Foram coletados aproximadamente $10 \mathrm{~m}^{3}$ de lixiviado do ponto mais próximo à tubulação de chegada do lixiviado bruto à lagoa de equalização, por meio de um caminhão-tanque. 


\section{Tratamento preliminar por stripping de amônia seguido de tratamento biológico por lodos ativados}

O tratamento do lixiviado foi realizado em duas etapas. Na primeira, empregou-se a técnica de stripping de amônia em sistema de bateladas sequenciais, realizada em dois reatores com capacidade volumétrica de $1 \mathrm{~m}^{3}$, constituídos de paletas giratórias de polietileno e aço inoxidável com rotação aproximada de 5,5 rpm, para remoção parcial de $\mathrm{N}$-amoniacal. O critério de parada nessa etapa de pré-tratamento consistiu na remoção de aproximadamente $50 \%$ do $\mathrm{N}$-amoniacal inicial e resultou em tempo médio de operação de 20 dias.

$\mathrm{Na}$ segunda etapa, utilizou-se o tratamento biológico por lodos ativados, composto de fase aeróbia em reator com capacidade de 2 $\mathrm{m}^{3}$, com aeração realizada por meio de um compressor de ar e difusores construídos em tubulação perfurada de PVC, seguido de fase anóxica com adição de etanol, como fonte de carbono, dosado em função das concentrações de nitrito e nitrato residuais para desnitrificação por via curta e consequente remoção complementar da série nitrogenada. No final de cada batelada do tratamento biológico, o efluente sobrenadante foi transferido e armazenado/acumulado em tanque com capacidade de $10 \mathrm{~m}^{3}$ para a etapa de pós-tratamento.

\section{Pós-tratamento por coagulação e filtração ascendente em pedregulho}

O pós-tratamento do lixiviado tratado biologicamente foi realizado em instalação piloto de filtração ascendente em pedregulho (IPFAP), a qual foi constituída de sistema de alimentação de lixiviado tratado biologicamente, unidade de mistura rápida, sistema de filtração ascendente em pedregulho e sistemas de descarga e lavagem de filtro, conforme a Figura 1.

O sistema de alimentação foi utilizado para recalcar o lixiviado tratado biologicamente para a câmara de mistura rápida (CMR), localizada a uma altura de $6 \mathrm{~m}$, utilizando bomba dosadora eletromagnética (ProMinent - Concept Plus) com vazão de 12 L.h ${ }^{-1}$.

A CMR foi construída em acrílico, contendo três compartimentos interligados com orifícios de $25 \mathrm{~mm}$ de diâmetro. O primeiro compartimento foi utilizado para a entrada do lixiviado. O segundo compartimento foi projetado com as mesmas dimensões dos reatores estáticos

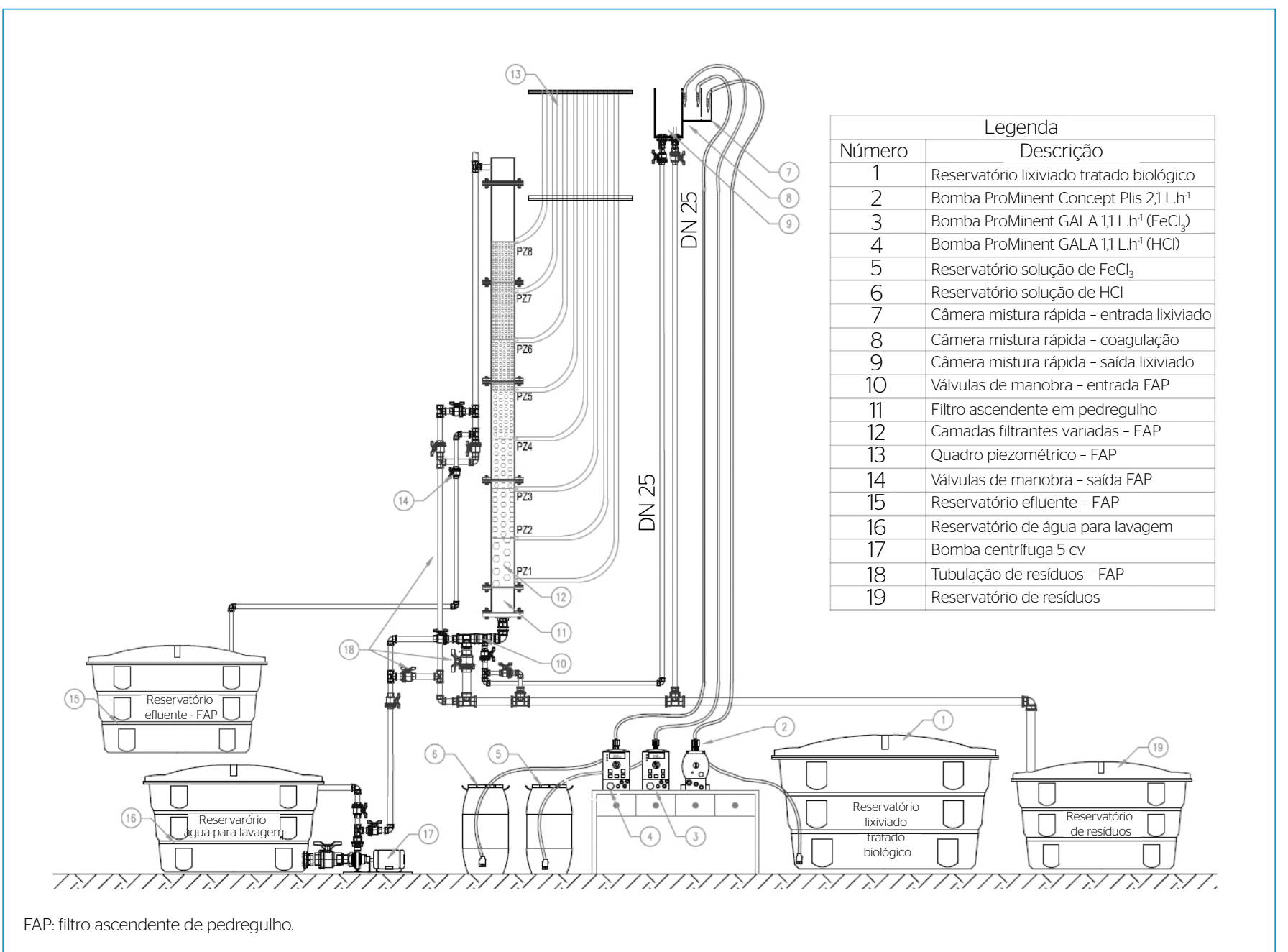

Figura 1 - Esquema da instalação piloto de filtração ascendente em pedregulho. 
do equipamento Jarteste, utilizado em ensaios preliminares para determinação das condições de coagulação química de maior eficiência, e foi provido de um agitador com paleta de hélice naval (Fisaton 713 D). Nesse compartimento, a mistura rápida ocorreu com gradiente de velocidade médio de mistura de $800 \mathrm{~s}^{-1}$, tempo de mistura rápida de 10 minutos e adição de produtos químicos através de bombas dosadoras eletromagnéticas (ProMinent - 1601): cloreto férrico (solução comercial com $42,35 \%$ de $\mathrm{FeCl}_{3} .6 \mathrm{H}_{2} \mathrm{O}$ e massa específica de $1,42 \mathrm{~kg} . \mathrm{L}^{-1}$ ) como coagulante químico e ácido clorídrico (solução comercial com $37 \%$ de $\mathrm{HCl}$ e massa específica de $1,187 \mathrm{~kg} \cdot \mathrm{L}^{-1}$ ) como acidificante para ajuste do pH de coagulação.

O último compartimento foi constituído de duas tubulações de saída, sendo uma utilizada como extravasor e a outra interligada diretamente ao fundo do filtro, a fim de possibilitar a alimentação do filtro ascendente de pedregulho. Nessa tubulação foi feita uma derivação, provida de registros de manobras, para que fosse realizada a pré-operação do sistema e o ajuste da vazão e das condições de coagulação química antes do início do ensaio. As condições mais adequadas de coagulação química foram determinadas pela construção do diagrama de coagulação, variando-se as dosagens de coagulante e o pH de coagulação em ensaios em reatores estáticos utilizando o equipamento Jarteste (Nova Ética - 218/6LDBE) (POZZETTI et al., 2013), tendo resultado em dosagem de ferro de 400 mg.L.-1 em pH 4.

O filtro ascendente de pedregulho (FAP) foi construído em chapas de acrílico de $6 \mathrm{~mm}$ de espessura com base quadrada de $25 \times 25 \mathrm{~cm}$ e altura de $281 \mathrm{~cm}$. O FAP foi constituído de 6 módulos superpostos, sendo dois módulos menores, de $15 \mathrm{~cm}$ de altura, para entrada de lixiviado coagulado e saída de lixiviado filtrado.

Para os ensaios (I a IV), foram aplicadas taxas de filtração constante de $15 \mathrm{~m}^{3} \cdot \mathrm{m}^{-2} \cdot \mathrm{dia}^{-1}$, o que correspondeu à vazão de $12 \mathrm{~L} \cdot \mathrm{h}^{-1}$. Em função dos resultados obtidos para cada composição granulométrica, foram pesquisadas, sucessivamente, quatro composições de meio filtrante (1 a 4), mantendo-se a composição das camadas de pedregulho e variando-se a granulometria das demais camadas, de acordo com a Tabela 1.
Para controle operacional, procedeu-se a coleta de amostras após a CMR a cada 15 minutos para monitoramento do $\mathrm{pH}$ de coagulação. Para avaliação da eficiência do sistema, realizou-se coleta de amostras do efluente filtrado a cada 15 minutos na primeira hora e a cada 30 minutos da segunda hora em diante, até o final da carreira de filtração. Foram monitorados, ao longo do experimento, os parâmetros de controle: $\mathrm{pH}$, perda de carga, turbidez e cor aparente.

Baseando-se em ensaios preliminares, foi definido um número de descargas de fundo intermediárias (DFIs) igual a 3, a fim de prolongar a carreira de filtração para duração mínima da ordem de 24 horas, resultando em 4 carreiras intermediárias de 6 horas, visando à simplicidade operacional do sistema. As DFIs foram realizadas com taxa média de aproximadamente $2.780 \mathrm{~m}^{3} \cdot \mathrm{m}^{-2} \cdot \mathrm{d}^{-1}$, duração média de 15 segundos e esgotamento total do filtro.

Os critérios de encerramento das carreiras de filtração estabelecidos foram: perda de carga máxima do FAP de $120 \mathrm{~cm}$ ou ocorrência de transpasse de flocos por meio da camada de areia.

Após encerramento da carreira, a lavagem do FAP foi efetuada em quatro etapas: execução de descarga de fundo; enchimento com água no sentido ascensional até o limite estabelecido de $36 \mathrm{~cm}$ a partir do topo da última camada de areia, seguida de aplicação de ar com taxa da ordem de $20 \mathrm{~L} \cdot \mathrm{s}^{-1} \cdot \mathrm{m}^{-2}$ durante 5 minutos; aplicação simultânea de água no sentido ascensional com taxa de $500 \mathrm{~m}^{3} \cdot \mathrm{m}^{-2} \cdot \mathrm{dia}^{-1} \mathrm{e}$ ar com taxa da ordem de $10 \mathrm{~L} \cdot \mathrm{s}^{-1} \cdot \mathrm{m}^{-2}$; aplicação de água no sentido ascensional com taxa de aproximadamente $1.130 \mathrm{~m}^{3} \cdot \mathrm{m}^{-2} \cdot \mathrm{dia}^{-1}$ por 5 minutos, limitando-se a expansão do meio até o limite de $36 \mathrm{~cm}$.

Com exceção da análise de nitrato, que foi realizada de acordo com o método proposto por Cataldo et al. (1975), os lixiviados antes e após cada tratamento foram caracterizados segundo métodos analíticos, descritos em American Public Health Association (APHA), American Water Works Association (AWWA) e Water Environment Federation (WEF) (2012) em relação aos parâmetros: $\mathrm{pH}$, cor aparente e verdadeira, DQO, nitrogênio Kjeldahl total (NKT), N-amoniacal e nitrito.

Tabela 1 - Composições do meio filtrante.

\begin{tabular}{l|c|c|c|c|}
\hline Ensaios & I & II & III \\
\hline \multirow{2}{*}{ Composição granulométrica FAP } & 1 & 2 & 3 \\
\cline { 2 - 5 } Areia fina (0,30-1,20 mm) & \multicolumn{2}{|c}{ Espessura (cm) } \\
\hline Areia grossa (0,6-2,4 mm) & - & 30 & 30 \\
\hline Pedrisco (2,4-4,8 mm) & - & 30 & 30 & 30 \\
\hline Pedregulho 1 (4,8-9,5 mm) & 30 & 30 & 30 & 30 \\
\hline Pedregulho 2 (9,5-19,0 mm) & 30 & 30 & 30 & 30 \\
\hline Pedregulho 3 (19-25 mm) & 30 & 30 & 30 \\
\hline Espessura total (cm) & 150 & 150 & 30 \\
\hline
\end{tabular}

FAP: Filtro ascendente em pedregulho. 
Complementarmente, para o ensaio IV (com composição granulométrica selecionada), foi constituída uma amostra composta com alíquotas do volume acumulado das carreiras intermediárias dos efluentes produzidos ao longo do tempo, e caracterizada especialmente em relação à matéria orgânica recalcitrante, utilizando-se os parâmetros: cor verdadeira, DQO e carbono orgânico total (COT).

\section{RESULTADOS E DISCUSSÃO}

A Tabela 2 apresenta os resultados da caracterização físico-química dos lixividos bruto e tratado biologicamente. Renou et al. (2008) apontam que lixiviados estabilizados usualmente apresentam $\mathrm{pH}>$ 7,5 e DQO $<4.000 \mathrm{mg}$. $\mathrm{L}^{-1}$. Comparando com os valores obtidos na caracterização do lixiviado bruto, pH de 8,9 e DQO de 1.466 mg.L-1 , é possível confirmar suas características de estabilização biológica, indicando assim baixa biodegradabilidade. Tal característica já era esperada, uma vez que no monitoramento do lixiviado desse mesmo aterro durante 6 meses, realizado por Felici et al. (2013), o valor médio da relação DBO/DQO obtida foi de 0,05 . Por outro lado, as características do lixiviado estabilizado utilizado neste trabalho diferem das comumente encontradas na literatura em relação à série nitrogenada (FELICI et al., 2013), pois no momento da coleta a lagoa de equalização estava sob aeração, contribuindo assim para a redução da concentração do $\mathrm{N}$-amoniacal e aumento de nitrito e nitrato.
Após o tratamento por stripping de amônia seguido do tratamento biológico por lodos ativados, observa-se que grande parte do nitrogênio foi removida, com redução de $42 \%$ de NKT, $89 \%$ de N-amoniacal, $96 \%$ de nitrito e $98 \%$ de nitrato. Todavia, a matéria orgânica recalcitrante ainda permaneceu no lixiviado, evidenciada pelas baixas remoções e elevados valores residuais de cor verdadeira (3\% de remoção com valor residual de $3.968 \mathrm{uH}$ ) e de DQO (25\% de remoção com valor residual de $\left.1.101 \mathrm{mg} . \mathrm{L}^{-1}\right)$, comprovando assim a necessidade de pós-tratamento para esse efluente.

O resumo dos resultados obtidos nos ensaios I a IV é apresentado na Tabela 3. Para aplicação de taxa de filtração constante de $15 \mathrm{~m}^{3} \cdot \mathrm{m}^{-2} \cdot \mathrm{dia}^{-1}$, dosagem de 400 mg.L $\mathrm{L}^{-1}$ de ferro em pH 4,0; a eficiência de remoção de cor aparente variou de 99,7\% (ensaio I) a 98,9\% (ensaio IV), resultando em valores residuais de cor aparente entre 11 e $47 \mathrm{uH}$, respectivamente.

A composição granulométrica exerceu forte influência na duração das carreiras de filtração, bem como na qualidade do efluente produzido. De acordo com os resultados do ensaio I (Figura 2), a adoção de camada filtrante de $60 \mathrm{~cm}$ de areia fina resultou em duração da carreira de filtração de apenas 14,3 horas, mesmo com execução de três descargas de fundo intermediárias.

Por outro lado, no ensaio II, a composição granulométrica do material filtrante constituída de pedrisco e areia grossa não foi capaz de reter os flocos formados ao longo do tempo, o que concorreu para a ocorrência do transpasse, com consequente aumento de cor aparente

Tabela 2 - Caracterização físico-química do lixiviado.

\begin{tabular}{l|c|c|c|c}
\multirow{2}{*}{ Parâmetro } & \multirow{2}{*}{ Unidade } & \multicolumn{2}{|c}{ Lixiviado } & Remoção (\%) \\
\cline { 3 - 5 } $\mathrm{pH}$ & & Bruto & 8,5 & - \\
\hline Cor verdadeira & - & 8,9 & 3968 & 3 \\
\hline Cor aparente & $\mathrm{uH}$ & 4078 & 4290 & 11 \\
\hline DQO & $\mathrm{uH}$ & 4684 & 1101 & 25 \\
\hline NKT & $\mathrm{mg} \cdot \mathrm{L}-1$ & 1466 & 109,5 & 42 \\
\hline N-amoniacal & $\mathrm{mg.L-1}$ & 187,8 & 7,3 & 89 \\
\hline Nitrito & $\mathrm{mg.L-1}$ & 71,7 & 2,3 & 96 \\
\hline Nitrato & $\mathrm{mg.L-1}$ & 65,2 & 3,9 & 98 \\
\hline
\end{tabular}

DQO: demanda química de oxigênio; NKT: nitrogênio Kjeldahl total.

Tabela 3 - Resumo dos resultados dos ensaios I a IV.

\begin{tabular}{|c|c|c|c|c|}
\hline \multirow{3}{*}{ Ensaio } & \multirow{2}{*}{ Granulometria da camada filtrante } & \multirow{3}{*}{$\begin{array}{l}\text { Condições } \\
\text { coagulação química }\end{array}$} & \multirow{2}{*}{ Duração da carreira de fitração } & Cor aparente residual \\
\hline & & & & mín-máx \\
\hline & Tipo & & (h) & (uH) \\
\hline । & 1 & \multirow{4}{*}{$\begin{array}{c}400 \text { mg.L-1 ferro } \\
\text { pH 4,O }\end{array}$} & 14,3 & $11-25$ \\
\hline$\|$ & $2^{*}$ & & 4,0 & $16-35$ \\
\hline III & $3^{*}$ & & 24,0 & $16-43$ \\
\hline IV & 4 & & 22,6 & $22-47$ \\
\hline
\end{tabular}

*Ensaio com ocorrência de transpasse. 
sem aumento significativo de perda de carga, resultando, assim, no encerramento da mesma em apenas 4 horas de operação (Figura 3). Dessa forma, pôde-se constatar a necessidade do emprego de areia de menor granulometria na composição do filtro ascendente.

No ensaio III, o material granular teve sua composição alterada para o tipo 3, acrescentando-se $30 \mathrm{~cm}$ de areia fina ao topo da camada filtrante, a fim de favorecer a retenção dos flocos e melhorar a qualidade do efluente produzido. Apesar de essa modificação ter proporcionado o aumento da duração da carreira de filtração, houve ocorrência de transpasse após 24,0 horas de operação, resultando no encerramento da carreira (Figura 4).
Assim, no ensaio IV, com o objetivo de impedir a ocorrência de transpasse, optou-se pelo acréscimo de mais $30 \mathrm{~cm}$ de areia fina ao topo da última camada, resultando na composição granulométrica tipo 4, com espessura total de $210 \mathrm{~cm}$ de camada granular.

Com essas alterações na composição da camada filtrante, pôde-se constatar que a adição de pedrisco e areia grossa no meio filtrante aumentou o tempo de caminhamento da frente de impurezas até a camada de areia fina e prolongou a duração da carreira de filtração, que no ensaio IV foi de 22,6 horas (Figura 5), quando o ensaio foi encerrado por perda de carga limite estabelecido em $120 \mathrm{~cm}$, sem ocorrência de transpasse.
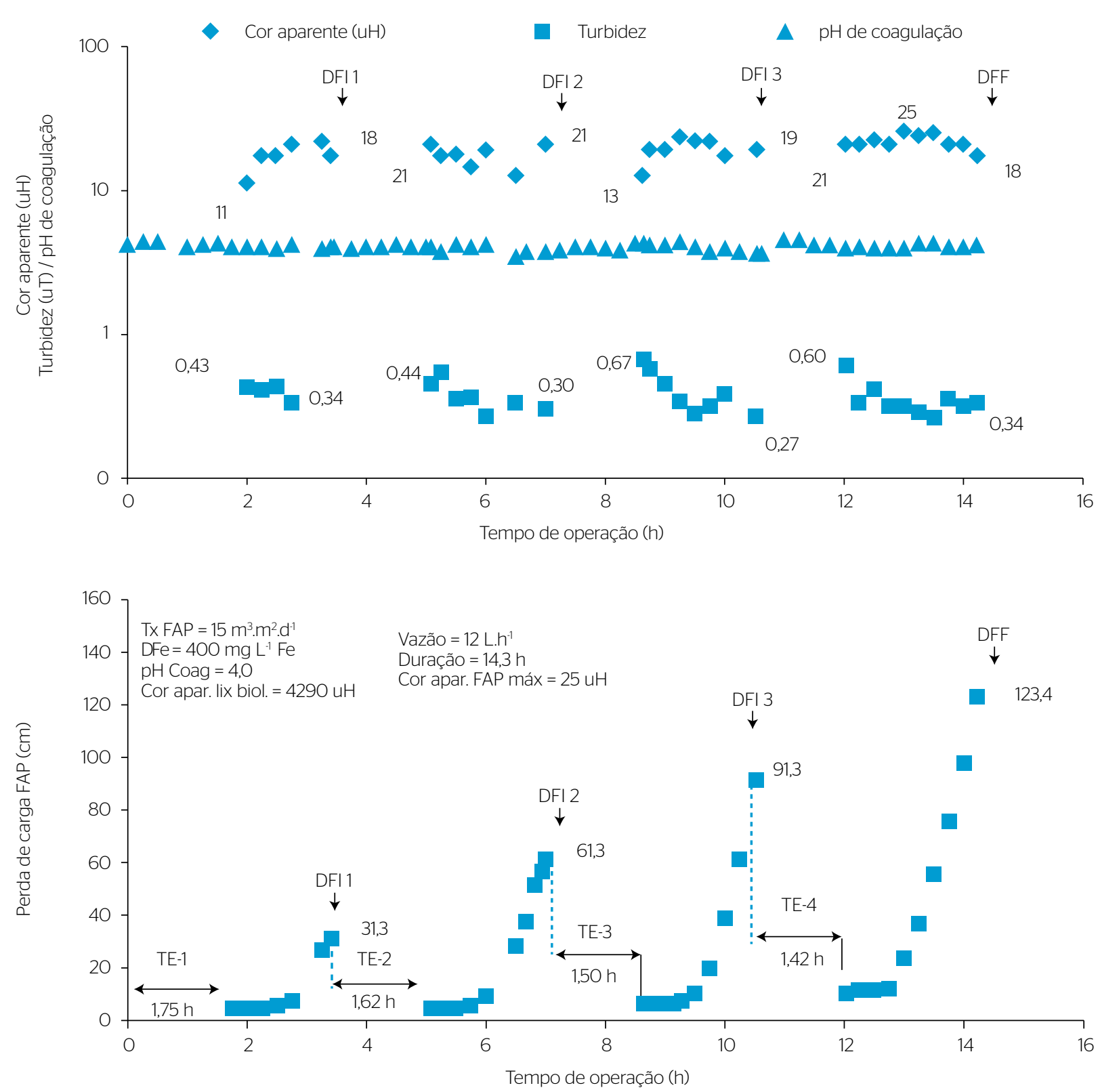

FAP: filtro ascendente em pedregulho; DFI: descarga de fundo intermediária; DFF: descarga de fundo final; TE: tempo de enchimento.

Figura 2 - Ensaio I: valores de cor aparente, turbidez, pH de coagulação e perda de carga em função da duração da carreira de filtração. 
A amostra composta, constituída de alíquotas do volume acumulado dos ciclos intermediários dos lixiviados produzidos ao longo do tempo no ensaio IV, apresentou remoção de $82,4 \%$ de DQO, diminuindo de 1.101 para $194 \mathrm{mg} . \mathrm{L}^{-1}$. Já a cor verdadeira teve um redução de 3.968 para $49 \mathrm{uH}$, correspondendo assim a 98,8\% de remoção.

Dessa forma, pôde-se constatar que todo o efluente produzido no ensaio IV apresentou qualidade compatível aos padrões de lançamento da Resolução nº 086/2013 (PARANÁ, 2013), a qual estabelece que a DQO de saída deve ser reduzida em $80 \%$ do valor de entrada, correspondendo ao valor de $293 \mathrm{mg} . \mathrm{L}^{-1}$. O mesmo foi observado para a cor verdadeira quando comparada aos padrões de enquadramento para águas doces classes 2 e 3 da Resolução n 357/2005 do Conselho Nacional do Meio Ambiente (CONAMA) (BRASIL, 2005) em relação à cor verdadeira, cujo limite estabelecido é de $75 \mathrm{uH}$.

Embora o parâmetro COT seja especificado na Resolução nº 357/2005 do CONAMA como padrão de enquadramento somente em corpos de águas salobras e salinas, com respectivos limites de 5 e 10 mg.L $\mathrm{L}^{-1}$, para ambas as classes 2 e 3, esse é o parâmetro mais confiável para quantificação da matéria orgânica residual, nesse caso, recalcitrante. Assim, a amostra composta caracterizada em relação aos parâmetros cor verdadeira e DQO foi, complementarmente, analisada em relação ao COT e apresentou, para o ensaio IV, valores residuais de $52 \mathrm{mg} . \mathrm{L}^{-1}$ de COT

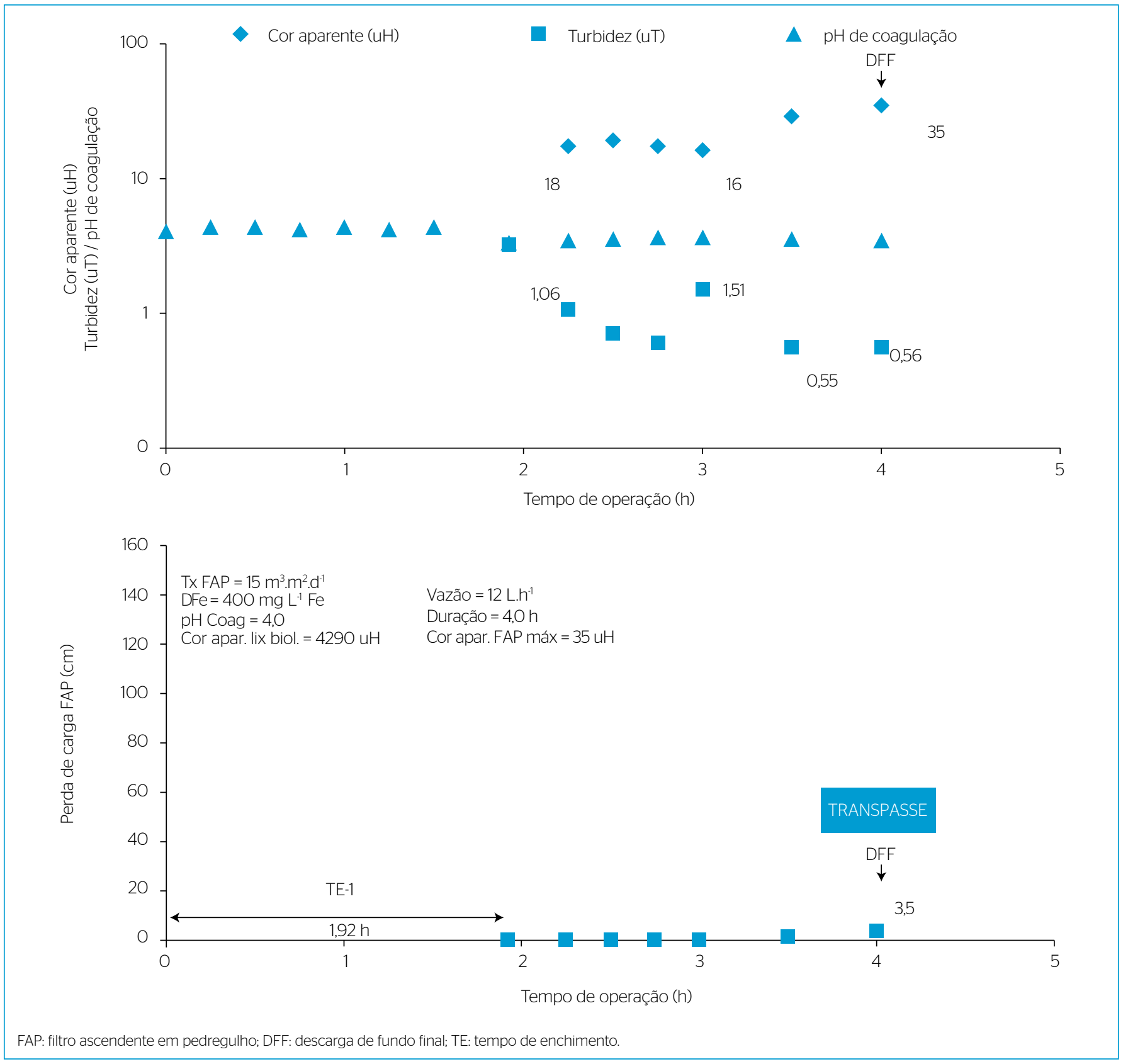

Figura 3 - Ensaio Il: valores de cor aparente, turbidez, pH de coagulação e perda de carga em função da duração da carreira de filtração. 
(remoção de 94,3\%). Resultados da mesma ordem de grandeza foram obtidos por Pozzetti et al. (2013), que utilizaram o lixiviado proveniente do mesmo aterro sanitário, com características semelhantes ao utilizado neste trabalho, para o pós-tratamento por coagualação-floculação-sedimentação em escala de bancada e reatores estáticos/jarteste. A condição de máxima eficiência para a coagulação química ocorreu com dosagem de $400 \mathrm{mg} . \mathrm{L}^{-1}$ de ferro, $\mathrm{pH}$ 4,0 e tempo de sedimentação de 1 hora, o que resultou em cor verdadeira residual de $38 \mathrm{uH}$ (remoção de 99\%), DQO residual de 292 mg.L-1 (remoção de 74\%) e carbono orgânico dissolvido (COD) residual de 23 mg.L-1 (remoção de 97\%).
Estes resultados comprovam que, em termos qualitativos, a filtração ascendente precedida de coagulação constitui uma alternativa técnica viável para pós-tratamento de lixiviados estabilizados em escala real, especialmente em aterros de médio e grande porte.

\section{CONCLUSÕES}

A composição granulométrica do filtro ascendente exerceu forte influência na duração das carreiras de filtração, bem como na qualidade do efluente, podendo-se constatar a necessidade do emprego
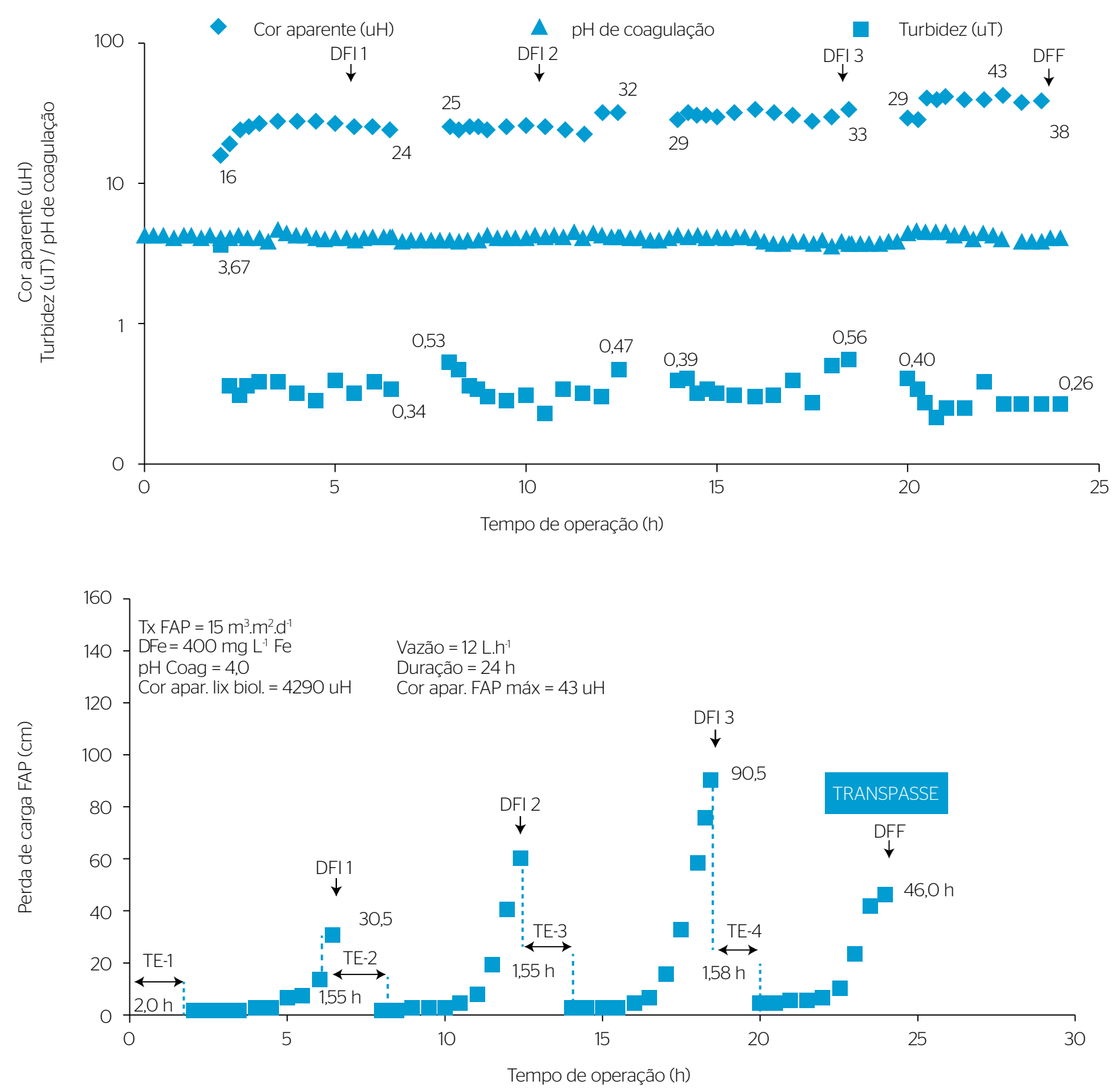

FAP: filtro ascendente em pedregulho; DFI: descarga de fundo intermediária; DFF: descarga de fundo final; TE: tempo de enchimento.

Figura 4 - Ensaio III: valores de cor aparente, turbidez, pH de coagulação e perda de carga em função da duração da carreira de filtração. 
de pedregulho e areia fina na composição do meio filtrante, a fim de garantir a eficiência do tratamento de lixiviado estabilizado por coagulação e filtração ascendente.

A concepção técnica de pós-tratamento por coagulação seguida da filtração com a composição granulométrica definida neste trabalho (tipo 4) foi eficiente para a remoção de matéria orgânica recalcitrante, com remoções de $82,4 \%$ de DQO (com valor residual de 194 mg. $\mathrm{L}^{-1}$ ), de $98,8 \%$ de cor verdadeira (com valor residual de $49 \mathrm{uH}$ ), de 94,3\% de COT (com valor residual de $52 \mathrm{mg} . \mathrm{L}^{-1}$ ) e duração de carreira de filtração de 22,6 horas, sem ocorrência de transpasse (ensaio IV).
Há necessidade de continuidade dos estudos quanto aos demais poluentes remanescentes, tais como cloretos, metais pesados e especiações da matéria orgânica recalcitrante. Ressalta-se ainda a importância do estudo de outros tipos de lixiviados associados a esse pós-tratamento e da inclusão de avaliação ecotoxicológica, considerando as legislações vigentes, os impactos ambientais e os riscos à saúde pública.

\section{FONTE DE FINANCIAMENTO}

Coordenação de Aperfeiçoamento de Pessoal de Nível Superior (CAPES); Financiadora de Estudos e Projetos (FINEP).

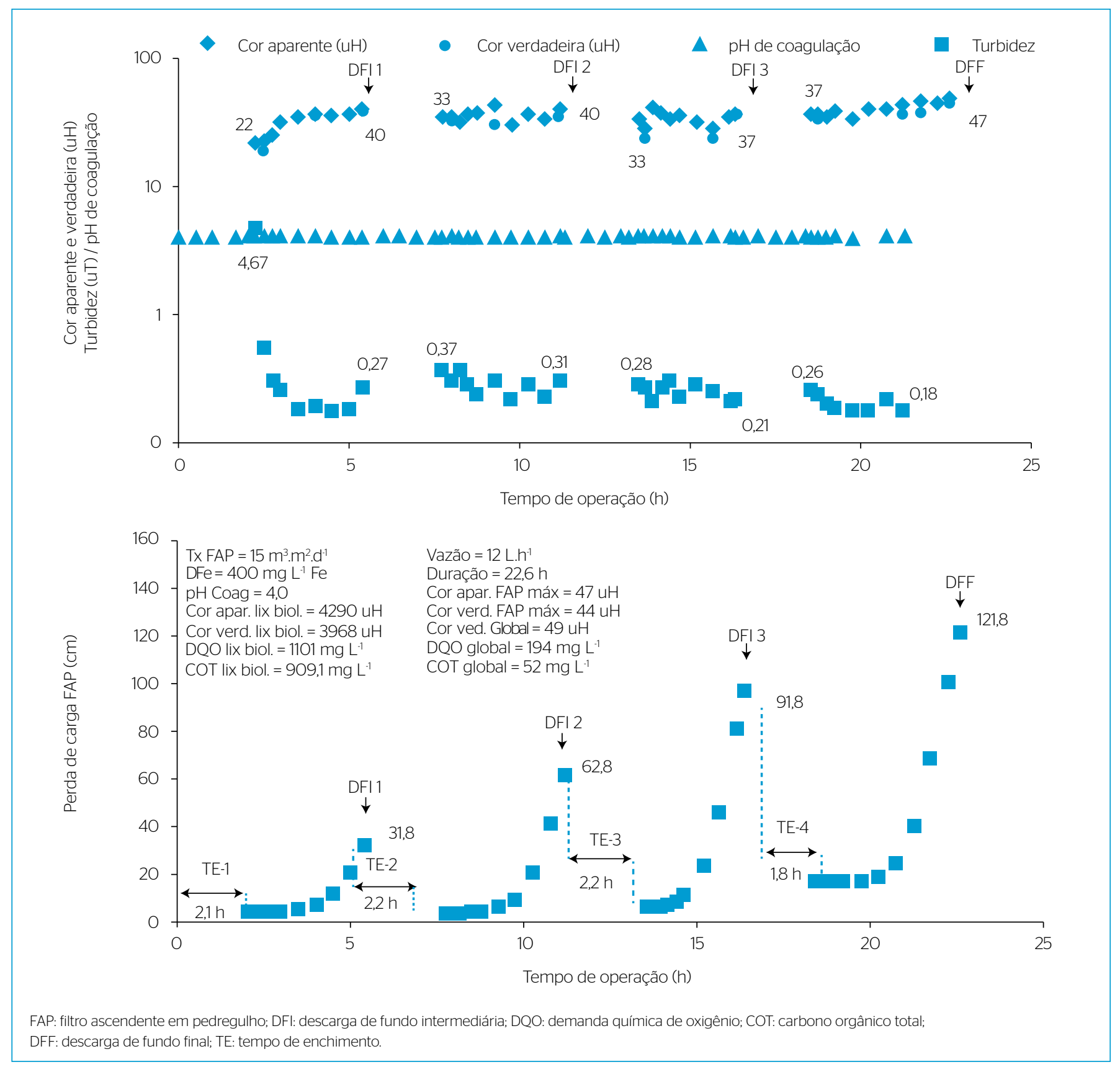

Figura 5 - Ensaio IV: valores de cor aparente e verdadeira, turbidez, pH de coagulação e perda de carga em função da duração da carreira de filtração. 


\section{REFERÊNCIAS}

AMERICAN PUBLIC HEALTH ASSOCIATION (APHA); AMERICAN WATER WORKS ASSOCIATION (AWWA); WATER ENVIRONMENT FEDERATION (WEF). (2012) Standard Methods for the Examination of Water and Wastewater. 21. ed. Washington, D.C. 1.082 p.

AMOKRANE, A.; COMEL, C.; VERON, J. (1997) Landfill leachates pretreatment by coagulation-flocculation. Water Research, v. 31, n. 11, p. 2775-2782. https://doi.org/10.1016/S0043-1354(97)00147-4

ASSOCIAÇÃO BRASILEIRA DE EMPRESAS DE LIMPEZA PÚBLICA E RESÍDUOS ESPECIAIS (ABRELPE). (2015) Panorama dos resíduos sólidos no Brasil 2015. São Paulo: ABRELPE. 88 p.

AZIZ, H.A.; ALIAS, S.; ADLAN, M.N.; FARIDAH, A.H.; ASAARI, A.H.; ZAHARI, M.S.M. (2007) Colour removal from landfill leachate by coagulation and flocculation processes. Bioresource Technology, v. 98, n. 1, p. 218-220. https://doi.org/10.1016/j. biortech.2005.11.013

BAIG, S.; COULOMB, I.; COURANT, P.; LIECHTI, P. (1999) Treatment of landfill leachates: Lapeyrouse and Satrod case studies. Ozone: Science \& Engineering, v. 21, n. 1, p. 1-22. https://doi. org/10.1080/01919519908547255

BRASIL. (2005) Ministério do Meio Ambiente. Conselho Nacional de Meio Ambiente. Resolução no 357, 17 de março de 2005. Dispõe sobre a classificação dos corpos 146 de água e diretrizes ambientais para o seu enquadramento, bem como estabelece as condições e padrões de lançamento de efluentes, e dá outras providências. Brasília: Ministério do Meio Ambiente.

CASTILHOS JUNIOR, A.B.; DALSASSO, R.L.; ROHERS, F. (2010) Prétratamento de lixiviados de aterros sanitários por filtração direta ascendente e coluna de carvão ativado. Engenharia Sanitária Ambiental, v. 15, n. 4, p. 385-392. http://dx.doi.org/10.1590/S141341522010000400011

CATALDO, D.A.; MAROON, M.; SCHRADER, L.E.; YOUNGS, V.L. (1975) Rapid colorimetric determination of nitrate in plant tissue by nitration of salicylic acid. Communications in Soil Science and Plant Analysis, v. 6, n. 1, p. 71-80. https://doi. org/10.1080/00103627509366547

DIAMADOPOULOS, E. (1994) Characterization and treatment of recirculation-stabilized leachate. Water Research, v. 28, n. 12, p. 2439-2445. https://doi.org/10.1016/0043-1354(94)90062-0

DI BERNARDO, L.; DANTAS, A.D.B. (2005) Métodos e técnicas de tratamento de água. 2. ed. São Carlos: RiMa. 792 p.

FELICI, E.M.; KURODA, E.K.; YAMASHITA, F.; SILVA, S.M.C.P. (2O13) Remoção de carga orgânica recalcitrante de lixiviado de resíduos sólidos urbanos pré-tratado biologicamente por coagulação química-floculação-sedimentação. Engenharia Sanitária e Ambiental, v. 18, n. 2, p. 177-184. http://dx.doi.org/10.1590/S141341522013000200010
HUO, S.; XI, B.; YU, H.; HE, L.; FAN, S.; LIU, H. (2OO8) Characteristics of dissolved organic matter (DOM) in leachate with different landfill ages. Journal of Environmental Science, v. 20, n. 4, p. 492-498. https://doi.org/10.1016/S1001-0742(08)62085-9

KAWAHIGASHI, F.; MENDES, M.B.; ASSUNÇÃO JÚNIOR, V.G.; GOMES, V.H.; FERNANDES, F.; HIROOKA, E.Y.; KURODA, E.K. (2014) Pós-tratamento de lixiviado de aterro sanitário com carvão ativado. Engenharia Sanitária e Ambiental, v. 19, n. 3, p. 235-244. http://dx.doi. org/10.1590/S1413-41522014019000000652

KIETLINSKA, A.; RENMAN, G. (2005) An evaluation of reactive filter media for treating landfill leachate. Chemosphere, v. 61, n. 7, p. 933-940. https://doi.org/10.1016/j. chemosphere.2005.03.036

KJELDSEN, P.; BARLAZ, M.A.; ROOKER, A.P.; BAUN, A.; LEDIN, A.; CHRISTENSEN, T.H. (2002) Present and long-term composition of MSW landfill leachate: a review. Critical Reviews in Environmental Science and Technology, v. 32, n. 4, p. 297-336. https://doi. org/10.1080/10643380290813462

KURODA, E.K.; DI BERNARDO, L.; PAULA, D. (2003) Dupla filtração com filtro ascendente em pedregulho e em areia grossa para tratamento de água. Engenharia Sanitária e Ambiental, v. 8, n. 4, p. 221-238.

LI, H.; ZHOU, S.; SUN, Y.; FENG, P.; LI, J. (2009) Advanced treatment of landfill leachate by a new combination process in a full-scale plant. Journal of Hazardous Materials, v. 172, n. 1 , p. $408-415$

LINDE, K.; JÖNSSON, A.; WIMMERSTEDT, R. (1995) Treatment of three types of landfill leachate with reverse osmosis. Desalination, v. 101, n. 1, p. 21-30. https://doi.org/10.1016/00119164(95)00004-L

MALER, C.L.; SIMIONATO, L.R.; SANTOS, T.A.; FERNANDES, F. (2015) Sequência de tratamentos para lixiviado de aterro sanitário utilizando os processos físico-químico convencional e Fenton como pós-tratamento. Revista DAE, v. 199, p. 47-57. http://dx.doi. org/10.4322/dae.2014.145

MARAÑÓN, E.; CASTRILLÓN, L.; FERNÁNDEZ-NAVA, Y.:; FERNÁNDEZ-MENDEZ, A.; FERNÁNDEZ-SÁNCHEZ, A. (2008) Coagulation-flocculation as a pretreatment process at a landfill leachate nitrification-denitrification plant. Journal of Hazardous Materials, v. 156, n. 1-3, p. 538-544. http://dx.doi.org/10.1016/j. jhazmat.2007.12.084

PARANÁ. (2013) Conselho Estadual do Meio Ambiente. Resolução no 086/2013 - CEMA. Estabelece diretrizes e critérios orientadores para o licenciamento e outorga, projeto, implantação,operação e encerramento de aterros sanitários, visando o controle da poluição, da contaminação e a minimização de seus impactos ambientais e dá outras providências. Curitiba: Conselho Estadual do Meio Ambiente. 
POZZETTI, J.D.C.; MENDES, M.B.; FUJII, E.H.; KASHIGOE, A.S.H.; KURODA, E.K. (2013) Coagulação química de lixiviado estabilizado de aterro sanitário. In: CONGRESSO BRASILEIRO DE ENGENHARIA SANITÁRIA E AMBIENTAL, 27., 2013, Goiânia. Anais... Rio de Janeiro: ABES. p. 21-30.

RENOU, S.; GIVAUDAN, J.G.; POULAIN, S.; DIRASSOUYAN, F.; MOULIN, P. (2008) Landfill leachate treatment: Review and opportunity. Journal of Hazardous Materials, v. 150, n. 3, p. 468-493. https://doi.org/10.1016/j.jhazmat.2007.09.077
TATSI, A.A.; ZOUBOULIS, A.I.; MATIS, K.A.; SAMARAS, P. (2003) Coagulation-flocculation pre-treatment of sanitary landfill leachate. Chemosphere, v. 53, n. 7, p. 737-744. http://dx.doi.org/10.1016/S00456535(03)00513-7

WANG, F.; SMITH, D.W.; EL-DIN, M.G. (2003) Application of advanced oxidation methods for landfill leachate treatment. Journal of Environmental Engineering and Science, v. 2, n. 6, p. 413-427. https:// doi.org/10.1139/sO3-058 